\title{
China's dimming and brightening: evidence, causes and hydrological implications
}

\author{
Y. W. Wang ${ }^{1,2}$ and Y. H. Yang ${ }^{1}$ \\ ${ }^{1}$ Key Laboratory of Agricultural Water Resources, Hebei Laboratory of Agricultural Water-saving, Center for Agricultural \\ Resources Research, Institute of Genetics and Developmental Biology, Chinese Academy of Sciences, 286 Huaizhong Road, \\ Shijiazhuang 050021, China \\ ${ }^{2}$ University of Chinese Academy of Sciences, Beijing 100049, China
}

Correspondence to: Y. H. Yang (yonghui.yang@ @ sjziam.ac.cn)

Received: 19 July 2013 - Revised: 28 October 2013 - Accepted: 16 December 2013 - Published: 28 January 2014

\begin{abstract}
There is growing evidence that, corresponding to global dimming and brightening, surface solar radiation and sunshine hours over China have undergone decadal fluctuations during the 1960s-2000s. The results of a number of these analyses are, however, very different. In this study, we synthesize reliable results and conclusively address recent advances and insufficiencies in studies on dimming and brightening in China. A temporally and spatially prevalent dimming trend is noted in surface solar radiation, direct solar radiation and sunshine hours since the 1960s. Meanwhile, the changing trend in diffuse solar radiation is less pronounced. Increasing anthropogenic aerosol loading is regarded as the most plausible explanation for China's dimming. The brightening trend since 1990 , which mainly occurs in southeastern China and in the spring season, is weak and insignificant. The reverse in the solar radiation trend is associated with climate change by cloud suppression and slowdown in anthropogenic emissions. The future solar radiation trend in China could largely depend on the development of air quality control. Other potential driving factors such as wind speed, water vapor and surface albedo are also non-negligible in specific regions of China. Hydrological implications of dimming and brightening in China lack systematic investigation. However, the fact that solar radiation and pan evaporation trends in China track a similar curve in 1990 further suggests that the pan evaporation paradox could be partly resolved by changes in solar radiation.
\end{abstract}

Keywords. Atmospheric composition and structure (aerosols and particles) - hydrology (water-energy interactions) - meteorology and atmospheric dynamics (radiative processes)

\section{Introduction}

Incoming solar radiation is either reflected back to the outer space or absorbed by Earth's atmosphere and surface (IPCC, 2007). The absorbed fraction is the primary energy source that governs a wide range of physical, biological and chemical processes on our planet, including climate systems, hydrological cycle, plant growth, etc. (Wild, 2009, 2012a; Wild et al., 2012). Human activity increasingly releases tiny particles and greenhouse gases into the atmosphere, which in turn gradually modifies climate trends and energy flows in the atmosphere (Ramanathan et al., 2001; Wild, 2012b). Aerosol load increase in the atmosphere could induce stronger reflection of incoming solar radiation and decline in the amount of solar radiation absorbed by the surface (the so-called surface solar radiation, SSR). This phenomenon, popularly known as "global dimming", was observed in the 1950s-1980s with a magnitude ranging from 3 to $9 \mathrm{~W} \mathrm{~m}^{-2}$ at widespread locations across the world (Wild, 2012a), especially in large urban areas (Alpert et al., 2005). It is important to note that the term "global" in "global dimming" originally referred to "global radiation" (a synonym of SSR), rather than depicting the spatial scale of the globe (Wild, 2009). Through counteracting the increase in thermal radiation resulted from increasing greenhouse gases, global dimming, the reduction in radiative energy at Earth's surface, could mask the effect of global warming (Wild, 2012a).

Recent studies have shown that dimming did not persist into the 1990s, which instead transitioned into brightening in many regions of the world (Pinker et al., 2005; Wild et al., 2005). The recovery in SSR (in the range of 
1-4 $\mathrm{W} \mathrm{m}^{-2}$ ) mainly occurred in heavily industrialized regions (Wild, 2012a). In some non-industrialized countries (e.g., India and Zimbabwe), dimming is still being experienced (Wild et al., 2005). A similar trend was observed in sunshine hours ( $\mathrm{SH}$ ) in the contiguous United States (Angell and Korshover, 1978), western Europe (Sanchez-Lorenzo et al., 2008) and Japan (Stanhill and Cohen, 2008) since the 1980s and earlier. SH, which quantifies the length of time with direct solar radiation $\geq 120 \mathrm{~W} \mathrm{~m}^{-2}$ in each day, is a widely used proxy for SSR.

Two fundamental ways to change SSR include (1) externally changing incoming solar radiation by changing Earth's orbital parameters or solar output; and (2) internally changing the reflected fraction of solar radiation via changing cloud characteristics, radiatively active gases (especially water vapor), aerosol masses and optical properties or surface albedo (IPCC, 2007; Wild, 2009). The effects of Earth's orbital parameters and water vapor on observed decadal variations in SSR are largely negligible. This is because Earth's orbital parameters vary substantially on geological timescales greater than $10000 \mathrm{yr}$, and the magnitude of change in water vapor in recent decades is insufficient for a significant fluctuation in SSR (Hoyt and Schatten, 1993; Ramanathan and Vogelmann, 1997; Solomon et al., 2010). Based on IPCC (2007) estimates, among all the negative radiative forcings resulted from human activities (e.g., total aerosol, surface albedo and ozone), aerosols induce the largest effect. To a great extent, therefore, global dimming and brightening should be caused by clouds and aerosols, which respectively denote the impact of climate change and anthropogenic disturbances (Shi et al., 2008; Gilgen et al., 2009; Ohmura, 2009; Streets et al., 2009; Wild, 2009; Xia, 2010 b). So far, it remains inconclusive whether clouds or aerosols are the main driver of recent changes in SSR. Increasing studies tend to support the concept that while clouds effectively modulate SSR at annual scale, pollution-related aerosols determine the variability of SSR at decadal scale (Qian et al., 2006, 2007; Wang et al., 2012b; Wang et al., 2013). Generally, global and regional average trends in SSR are in line with those in anthropogenic aerosol emissions (Stern, 2006; Streets et al., 2006, 2009; Wild, 2012a).

Variations in SSR could alter the latent heat flux and evaporation energy equivalent, which in turn changes the intensity of the hydrological cycle (Ramanathan et al., 2001; Wild, 2009, 2012a; Wild and Liepert, 2010). Since the 1950s, declines in pan evaporation have been detected not only in the Northern Hemisphere (Peterson et al., 1995; Chattopadhyay and Hulme, 1997; Liu et al., 2004), but also in the Southern Hemisphere (Roderick and Farquhar, 2005; Rayner, 2007). This is contrary to the expectation that global warming increases evaporation from terrestrial water bodies. This discrepancy between observations and expectations is termed "pan evaporation paradox" (Brutsaert and Parlange, 1998). Increasingly, research proposes that the downward pan evaporation trend is rather not a real paradox but simply a response to global dimming (Roderick and Farquhar, 2002; Liu et al., 2004; Qian et al., 2006).

This review therefore attempts to conclusively address the evidence of dimming and brightening in China, determine the primary driver from the two most likely candidates of clouds and aerosols, and discuss the possible implications of dimming and brightening for pan evaporation processes.

\section{Evidence of dimming and brightening in China}

\subsection{Dimming and brightening in surface solar radiation}

The national solar radiation monitoring network, consisting of 122 stations in mainly urban or suburb regions across China (Fig. 1), was established in 1957 (Liang and Xia, 2005). The solar radiation instruments were later updated. Before 1993, solar radiation instruments were developed after the models of the former Soviet Union. These instruments included the Yanishevsky thermoelectric pyranometer for measuring SSR and diffuse solar radiation (DfSR) and the Yanishevsky thermoelectric actinometer for measuring direct solar radiation (DiSR) (Xia, 2010a; Ye et al., 2010; Tang et al., 2011), with respective error estimates of $\leq 5 \%$ and $\leq 3 \%$ (Shi et al., 2008). China started making its own instruments after 1993 and replaced the SSR/DfSR recorders with the DFY-4 pyranometer and the DiSR recorder with the DFY-3 pyrheliometer (Xia, 2010a; Ye et al., 2010; Tang et al., 2011), with errors not exceeding $5 \%$ and $2 \%$, respectively (Shi et al., 2008). Data recorded by the instruments are governed by China Meteorological Administration (CMA) and are available at China Meteorological Data Sharing Service System (CMDS, http://cdc.cma.gov.cn/). Preliminary quality checks are also performed by CMA to ensure that both DiSR and DfSR are lower than SSR for daily data (see interpretation of documented data sets). However, the simple quality control criterion could not eliminate the potential accuracy issues related with instrument change, artificial operational factors and station location change (Shi et al., 2008). In an attempt to resolve this issue, Shi et al. (2008) introduced a set of quality assessment (QA) algorithms, including a physical threshold test (QA1), a global radiation sunshine duration test (QA2), and a standard deviation test applied to time series of annually averaged solar global radiation (QA3). Recently, Tang et al. (2010) presented a new quality control scheme that includes two physical threshold tests, a test to remove monthlymean values with evident systematic and operational errors, and a test to eliminate the data with more insidious errors using the artificial neural network (ANN) method. Scientific results based on screened data by these strict quality controls have proven to be highly reliable.

Consistent with the global SSR trend, there is abundant evidence of the "from dimming to brightening" transition in the SSR trend in China in the past half century (Wild et al., 2005; Shi et al., 2008; Norris and Wild, 2009; Ohmura, 2009; Wang 


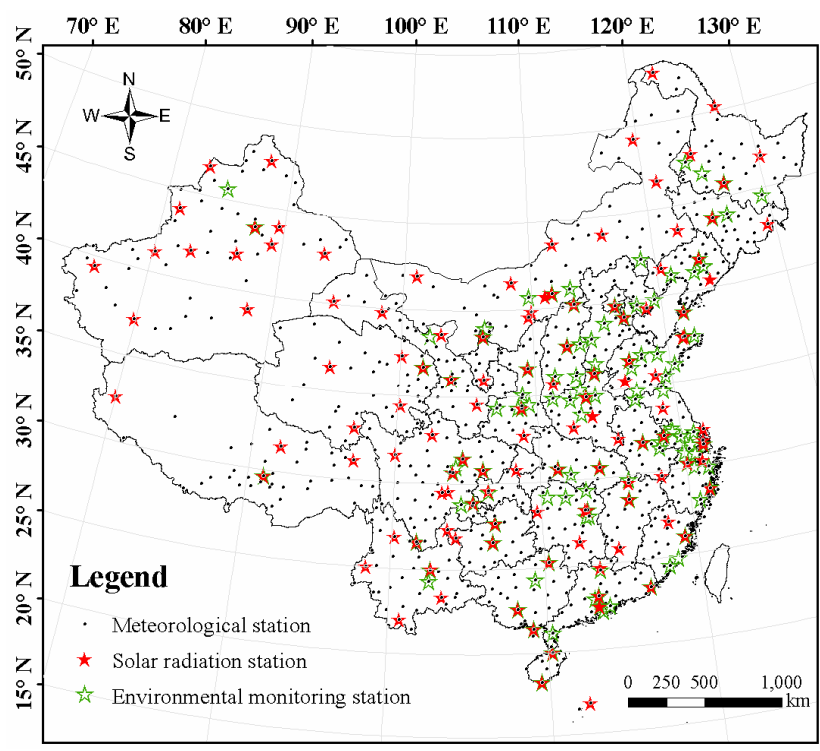

Fig. 1. Geographical locations of the 756 meteorological stations, 122 solar radiation stations and 120 environmental monitoring stations in China.

et al., 2009; Tang et al., 2011). However, several studies have noted a sustained decline of $3.1-4.9 \mathrm{~W} \mathrm{~m}^{-2}$ decade $^{-1}$ in linear trend of SSR across China in the 1950s-2000s (Liang and Xia, 2005; Qian et al., 2006; Yang et al., 2007; Yang and Yang, 2012). This is because marginal brightening (in the range of $0.4-4 \mathrm{~W} \mathrm{~m}^{-2}$ decade $^{-1}$ ) after 1990 fails to adequately compensate for strong dimming (in the range of 2.5$12 \mathrm{~W} \mathrm{~m}^{-2}$ decade $^{-1}$ ) in the 1950s-1980s (Table 1).

Ohmura (2009) proposed that the rate of dimming in China is the largest in the world. This inference is worth questioning when the dimming phase between the 1950s and 1980s in Table 1 is further examined. The magnitudes of SSR declines $\left(7-12 \mathrm{~W} \mathrm{~m}^{-2}\right.$ decade $^{-1}$ ) estimated by foreign scholars (Norris and Wild, 2009; Ohmura, 2009; Wild, 2012a) are particularly larger than those $\left(2.5-9.1 \mathrm{~W} \mathrm{~m}^{-2} \mathrm{decade}^{-1}\right)$ presented by Chinese researchers (Che et al., 2005; Shi et al., 2008; Wang et al., 2009; Tang et al., 2011). Especially in the recent study of Tang et al. (2011), which combines qualitycontrolled observation data with two radiation models; the decline in SSR across China is estimated at $2.5 \mathrm{~W} \mathrm{~m}^{-2}$ decade $^{-1}$ for the period 1961-1989 (Fig. 2a), which is no longer stronger in magnitude than the global average. These differences suggest the importance of data quality assessment and control. It is necessary to note that distinct data sets with varied spatial coverage and timescales could also influence the results of trend analyses of SSR. Dimming in China reached the lowest value in the 1980s (Wen et al., 2008; Wang et al., 2011; Ma et al., 2012). From Table 2, the most dramatic decline of SSR takes place in regions around southern, eastern and central China (Liu et al., 2004; Liang and Xia, 2005; Ohmura, 2006; Qian et al., 2006; Xia, 2010a;
Table 1. Magnitudes of trends in surface solar radiation $\left(\mathrm{W} \mathrm{m} \mathrm{m}^{-2}\right.$ decade $^{-1}$ ) in China. Note that \# denotes value not provided, ${ }^{a}$ is original value converted into common unit of $\mathrm{W} \mathrm{m}^{-2}$ decade $^{-1}$, and ${ }^{b}$ is value estimated by Wild (2009). Dark grey bars are for dimming trend and light grey bars for brightening trend.

\begin{tabular}{|c|c|c|c|c|c|c|c|}
\hline Reference & $\begin{array}{c}\text { Number } \\
\text { of sites }\end{array}$ & $1950 \mathrm{~s}$ & $1960 \mathrm{~s}$ & 1970s & $1980 \mathrm{~s}$ & $1990 \mathrm{~s}$ & $2000 \mathrm{~s}$ \\
\hline \multirow[t]{2}{*}{ Che et al. (2005) } & \multirow[t]{2}{*}{$\overline{64}$} & & \multicolumn{4}{|c|}{-4.5} & \\
\hline & & & \# & -9 & & \# & \\
\hline Liang and Xia (2005) & 42 & \multicolumn{5}{|c|}{$-4.9^{b}$} & \\
\hline Qian et al. (2006) & 85 & \multirow{2}{*}{\multicolumn{5}{|c|}{$\begin{array}{c}-3.1 \\
-3.4^{\mathrm{a}}\end{array}$}} & \\
\hline Yang et al. (2007) & 60 & & & & & & \\
\hline \multirow{2}{*}{ Shi et al. (2008) } & \multirow[t]{2}{*}{72} & \multicolumn{5}{|c|}{$-3.8^{\mathrm{b}}$} & \\
\hline & & \# & \multicolumn{3}{|c|}{$-7^{\mathrm{b}}$} & $2.7^{\mathrm{b}}$ & \\
\hline Norris and Wild (2009) & 23 & & & & & 4 & \\
\hline Ohmura (2009) & 66 & & \multicolumn{3}{|c|}{-12} & \# & \\
\hline Wang et al. (2009) & 30 & & \multicolumn{3}{|c|}{$-8.8^{\mathrm{a}}$} & $1.4^{\mathrm{a}}$ & \\
\hline \multirow[t]{2}{*}{ Tang et al. (2011) } & \multirow[t]{2}{*}{96} & & \multicolumn{4}{|c|}{-2.3} & \\
\hline & & & \multicolumn{3}{|c|}{-2.5} & \multicolumn{2}{|c|}{0.4} \\
\hline Wild et al. (2012a) & $\#$ & & -7 & & & & -4 \\
\hline Yang and Yang (2012) & 54 & \multicolumn{5}{|c|}{$\frac{1}{-4.5}$} & \\
\hline
\end{tabular}

Wang et al., 2011; Wild and Schmucki, 2011). In the western and northeastern parts of China, the decline in SSR is comparatively small (Shi et al., 2008; Wang et al., 2011).

However, the observed seasonal dimming trends are generally inconsistent. Based on screened data via quality assessment tests, Shi et al. (2008) concluded that the highest SSR decline is in winter $\left(4.82 \%\right.$ decade $\left.^{-1}\right)$, followed by autumn $\left(2.63 \%\right.$ decade $\left.^{-1}\right)$, summer $\left(2.5 \%\right.$ decade $\left.^{-1}\right)$ and spring $\left(1.39 \%\right.$ decade $\left.^{-1}\right)$. Whereas Wang et al. (2009) asserted that a significant decline occurs in the period from March to August, which accounts for $55-85 \%$ of the annual reduction. This finding was supported by Xia (2010a), who noted that summer and spring are the seasons with the strongest dimming rate in China. The uncertainties further stress the need for rigorous data-quality control in trend analyses of solar radiation. It is also worth noting that data sets used by Shi et al. (2008), Wang et al. (2009) and Xia (2010a) cover 122, 30 and 45 stations across China for the periods 1957-2000, 1961-2003 and 1961-2005, respectively. The different data sets added another layer of uncertainty to the trend analysis of seasonal SSR.

China's brightening depicts a quite different scenario. Contrary to dimming which continues to persist in northern China after 1990, Table 2 suggests that brightening is less spatially coherent and is mainly in southern China (Ohmura, 2006; Yang et al., 2007; Xia, 2010a; Wang et al., 2011; Wild and Schmucki, 2011). While brightening in southeastern China mainly occurs in spring, it mainly occurs during the other seasons in southwestern China (Xia, 2010a). There is still a debate on China's brightening in the academic sphere. A sustained brightening trend in China since 1990 was noted by Shi et al. (2008), Norris and Wild (2009), Ohmura (2009), Wang et al. (2009) - see Table 1. Excluding the effect of instrument change, Tang et al. (2011) argued that pervious studies overestimated the magnitude of brightening in China, as the trend in SSR since 1990 is inclined to stabilize rather than to rise (Fig. 2a). At the same time, Che et al. (2005) and Wild et al. (2009) reported a renewed 
Table 2. Regional characteristics of surface solar radiation trends in China for the 1960s-1980s (dimming phase) and 1990s-2000s (brightening phase).

\begin{tabular}{|c|c|c|c|c|c|}
\hline \multirow[b]{2}{*}{ Reference } & \multirow{2}{*}{$\begin{array}{l}\text { Number } \\
\text { of sites }\end{array}$} & \multicolumn{2}{|c|}{$1960 \mathrm{~s}-1980 \mathrm{~s}$} & \multicolumn{2}{|c|}{$1990 \mathrm{~s}-2000 \mathrm{~s}$} \\
\hline & & Strong dimming & Slight dimming & Dimming & Brightening \\
\hline Liu et al. (2004) & 85 & Southeastern China & & & \\
\hline Liang and Xia (2005) & 42 & Southern and eastern China & & & \\
\hline Ohmura (2006) & 66 & Southeastern China & Northwestern China & Northern China & Southeastern China \\
\hline Qian et al. (2006) & 85 & Central, eastern and southern China & & & \\
\hline Yang et al. (2007) & 60 & Eastern China & $\begin{array}{l}\text { Northeastern China } \\
\text { and Yunnan area }\end{array}$ & $\begin{array}{l}\text { Northern China, } \\
\text { and northern Xinjiang }\end{array}$ & $\begin{array}{l}\text { Southeastern and southwestern China, } \\
\text { Tibetan Plateau }\end{array}$ \\
\hline Shi et al. (2008) & 72 & Southern China & Northeastern and western China & & \\
\hline Xia (2010a) & 45 & Southeastern China & Southwestern China & Northern China & Southern China \\
\hline Wang et al. (2011) & 40 & Central and southern China & $\begin{array}{l}\text { Western arid/semi-arid } \\
\text { regions, northeastern China }\end{array}$ & $\begin{array}{l}\text { Northern China and western } \\
\text { arid/semi-arid regions }\end{array}$ & $\begin{array}{l}\text { Southern and southwestern } \\
\text { China, Tibetan Plateau }\end{array}$ \\
\hline Wild and Schmucki (2011) & 13 & Southeastern China & Northwestern China & Northwestern China & Southeastern China \\
\hline
\end{tabular}
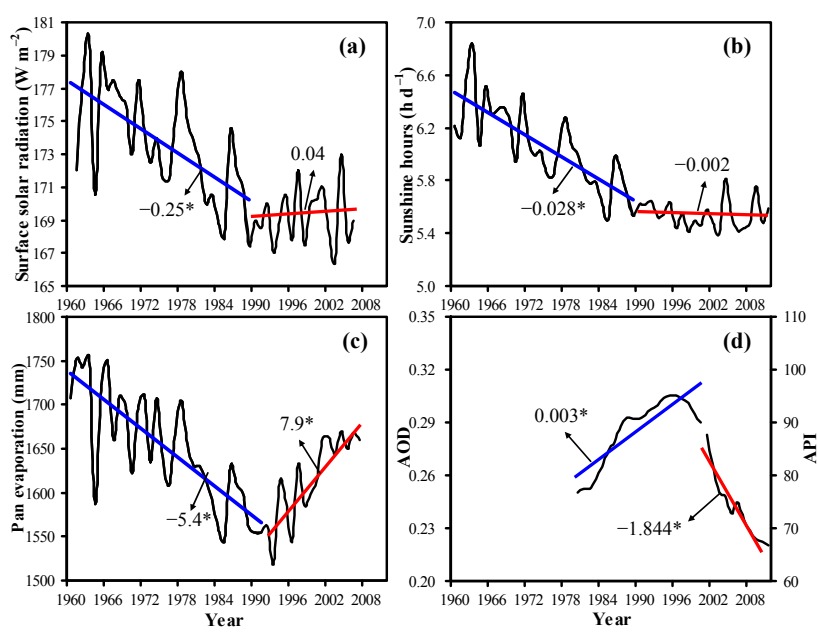

Fig. 2. Time series comparisons of annually averaged surface solar radiation (a, data from Tang et al., 2011), sunshine hours (b, data from Wang et al., 2013), pan evaporation (c, data from Liu et al., 2011a), AOD and API (d, data from Streets et al., 2008 and Wang et al., 2013 for 1980-2000 and 2001-2011, respectively) over China for the 1960s-2000s. Blue lines denote linear trends in dimming phase and red lines indicate linear trends in brightening phase. Values are trend slopes and asterisks denote a significant trend at the $95 \%$ confidence level.

dimming in China around 2000. All of these results come to an agreement that brightening in China is not as significant as in industrialized nations.

\subsection{Dimming and brightening in direct and diffuse solar radiation}

SSR is total shortwave radiation, constituting the direct component from the Sun (DiSR) and diffuse component from the sky (DfSR), incident on the horizontal surface (Xia et al., 2006; Qian et al., 2007; Wild, 2009). Variations in SSR closely correspond with the changes in the trend and magnitude of DiSR and DfSR.

In China, DiSR decreases in the range of 7.5$8.6 \%$ decade $^{-1} \quad$ (about $6.6 \mathrm{~W} \mathrm{~m}^{-2}$ decade $^{-1}$ ) during 1960s-1990s (Che et al., 2005; Liang and Xia, 2005; Shi et al., 2008) and moderately increases thereafter (Wen et al., 2008; Zhao et al., 2009). The geographical distribution of the variation in DiSR is very similar to that in SSR. It primarily declines in southern and eastern China but at much smaller rate in western and northeastern China (Liang and Xia, 2005; Shi et al., 2008; Zhao et al., 2009). Recent studies on seasonal trends in DiSR have drawn almost the opposite conclusions. Based on estimated DiSR from SH data obtained from 70 stations across China, Zhao et al. (2009) noted that the decline in DiSR is strongest in summer, followed by spring, autumn and winter for the period 1960-2005. However, based on observed DiSR data from 14 stations across China, Ma et al. (2011) observed that DiSR decline is most obvious in winter and autumn and insignificant in spring and summer for the period 1961-2009. The inconsistency of the results could be due to differences in the number of samples and length of periods of the analyses, as well as limitations in surface observation of DiSR in China.

DfSR shows a less pronounced trend of decline in China, which is at the average rate of $0.92-0.95 \%$ decade $^{-1}$ (about $0.72 \mathrm{~W} \mathrm{~m}^{-2}$ decade $^{-1}$ ) during the 1960s-1990s (Che et al., 2005; Shi et al., 2008). Annual average DfSR varies smoothly before 1980, significantly declines in 1981-1990 (Che et al., 2005), and then rebounds till 2010 (Ren et al., 2013). However, Qian et al. (2007) noted a steady DfSR increase in China under cloud-free skies for the period 19611992. DfSR depicts a more complex and heterogeneous spatial pattern. While in the 1960s-1990s sites with downward trends are mainly in northwestern China and the Tibetan Plateau, those with upward trends are largely in coastal areas and the middle and lower reaches of Yellow River (Liang and Xia, 2005; Shi et al., 2008; Ma et al., 2011). From 1980, the most evident increase and decrease in DfSR are respectively in the Tibetan Plateau and northwestern China (Ren et al., 2013). No obvious seasonal trend in DfSR is detected since 1960 (Liang and Xia, 2005; Ma et al., 2011). With the exception of spring, DfSR increases in trend in all the seasons during the period 1981-2010 (Ren et al., 2013). 
The reversal in SSR from dimming to brightening could therefore be due to changes in DiSR. It is well established that DiSR applies essentially to solar energy devices while DfSR applies more effectively to photosynthetic plants. This is because DfSR penetrates deeper into vegetation canopy and reaches a larger fraction of the biomass (Che et al., 2005; Pinker et al., 2005). Regardless of solar dimming, increasing DfSR as a result of stronger aerosol and cloud scattering could explain enhanced photosynthesis in forests or cropfields (Wild, 2012a; Wild et al., 2012).

\subsection{Dimming and brightening in sunshine hours}

Given that surface measurements of SSR are limited in time and space, SH, a surrogate for SSR, is often used because of its wider spatial distribution and longer temporal trends (Xia, 2010b). SH, the total amount of time when the Sun's disk is above the horizon and not obscured by naturally occurring obstacles, provides an old but robust measurement of radiation (Kaiser and Qian, 2002; Wild, 2009). Since 1951, SH is measured across China in 756 meteorological stations (Fig. 1). In the measurement history of SH in China, two kinds of instruments have been used. There is the Jordan recorder used for the period prior to 1954 and then the Campbell-Stokes sunshine recorder used after 1954 (Tao et al., 1997). It is, however, important to note that only data from the Campbell-Stokes sunshine recorder were used for the period of study; implying no change in instrument for measuring SH. The Campbell-Stokes sunshine recorder essentially consists of a glass sphere, set into a bowl, with a sun-burning trace on the bowl. It measures $\mathrm{SH}$ to the nearest $0.1 \mathrm{~h}$ from DiSR with a sufficient intensity $\left(0.12 \mathrm{cal} \mathrm{cm}^{-2} \mathrm{~min}^{-1}\right)$ to activate the recorder (Liang and Xia, 2005; Xia, 2010b; Ma et al., 2011). Thus, like DiSR, SH is sensitive to and frequently perturbed by clouds and haze; especially when the atmospheric optical path is longer, such as after sunrise and before sunset or in winter (Kaiser and Qian, 2002; Sanchez-Lorenzo et al., 2007).

A significant declining trend in $\mathrm{SH}$ at widespread sites across China during the last half century, especially in the 1980s, was first detected by Kaiser and Qian (2002). This trend was gradually reconfirmed by Che et al. (2005), Liang and Xia (2005), Cong et al. (2009), Zhao et al. (2009), Xia (2010b), Yin et al. (2010) and Wang et al. (2012). The decline in SH covers most of China and is mainly prevalent in regions around northern China, southeastern China and the Yangtze River delta (Ren et al., 2005; Zhao et al., 2010; Yu et al., 2011; Wang et al., 2012). For the period 1960-2011, the strongest dimming is in summer $\left(0.32 \mathrm{~h} \mathrm{~d}^{-1} \mathrm{decade}^{-1}\right)$, followed by winter $\left(0.23 \mathrm{~h} \mathrm{~d}^{-1} \mathrm{decade}^{-1}\right)$, autumn $\left(0.16 \mathrm{~h} \mathrm{~d}^{-1} \mathrm{decade}^{-1}\right)$ and spring $\left(0.11 \mathrm{~h} \mathrm{~d}^{-1} \mathrm{decade}^{-1}\right)$ (Fig. 4). Similar conclusions have been drawn by Xia (2010b), Zhao et al. (2010) and Yu et al. (2011).
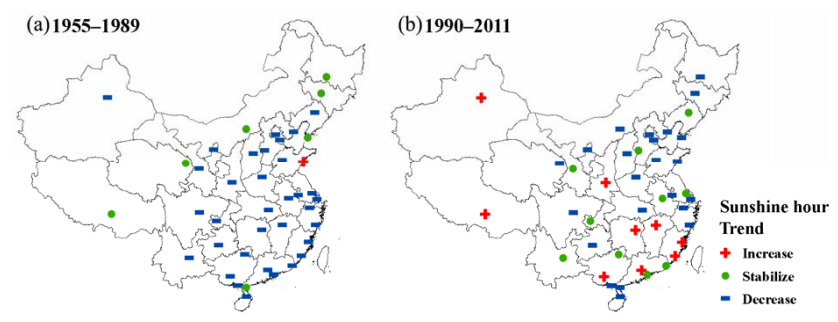

Fig. 3. Spatial patterns of sunshine hour trends over 42 meteorological stations across China for 1955-1989 (a) and 1990-2011 (b) (Wang et al., 2013).

Further examining the annual trend in $\mathrm{SH}$, a reversal from dimming to brightening is noted in the mid-1990s by Ren et al. (2005), Zhao et al. (2010) and Yu et al. (2011) corresponding to changes in the trends of DiSR and SSR. Wang et al. (2013) observed that instead of increasing, the SH trend in China's big cites leveled off or marginally declined by $0.02 \mathrm{~h} \mathrm{~d}^{-1}$ decade $^{-1}$ since 1990 , following a drastic decline by $0.28 \mathrm{~h} \mathrm{~d}^{-1}$ decade $^{-1}$ in the period $1960-1989$ (Fig. 2b). This observation is consistent with the "from dimming to leveling off" evidence of SSR in China advanced by Tang et al. (2011), which was based on high quality data (Fig. 2a). In the dimming phase of the 1960s-1980s, SH declines across $90 \%$ of China. The main exception to this trend is the Qinghai-Tibetan Plateau and northeastern China regions (Fig. 3a). SH declines the most in summer $\left(0.35 \mathrm{~h} \mathrm{~d}^{-1}\right.$ decade $\left.^{-1}\right)$ and winter $\left(0.34 \mathrm{~h} \mathrm{~d}^{-1}\right.$ decade $\left.^{-1}\right)$, and the least in autumn $\left(0.17 \mathrm{hd}^{-1} \mathrm{decade}^{-1}\right)$ (Fig. 4). In the leveling off phase of the 1990s-2000s, dimming only persists in one-half of the country, and brightening covers one-third of the country, especially in southeastern China (Fig. 3b). China's brightening mainly occurs in spring $\left(0.27 \mathrm{~h} \mathrm{~d}^{-1} \mathrm{decade}^{-1}\right)$ (Fig. 4). This has been verified in the studies of Wang et al. (2012, 2013) and Zhao et al. (2010).

In addition, Wang et al. (2013) compared SH trends between 42 cities and 42 surrounding counties across China and detected the dimming rate of $\mathrm{SH}$ at city scale $\left(0.20 \mathrm{~h} \mathrm{~d}^{-1}\right.$ decade $\left.^{-1}\right)$ is $0.06 \mathrm{~h} \mathrm{~d}^{-1}$ decade $^{-1}$ higher than that at county scale $\left(0.14 \mathrm{~h} \mathrm{~d}^{-1} \mathrm{decade}^{-1}\right)$ for the period 1955-2011. A similar conclusion has been reached by Li et al. (2012) for southwestern China for the period 1961-2009. These results are consistent with that from a global-scale analysis of annual SSR variations by Alpert et al. (2005), which shows a decline in $\mathrm{SH}$ of $0.41 \mathrm{~W} \mathrm{~m}^{-2} \mathrm{yr}^{-1}$ for highly populated sites and only of $0.16 \mathrm{~W} \mathrm{~m}^{-2} \mathrm{yr}^{-1}$ for sparsely populated sites $(<0.1$ million). 


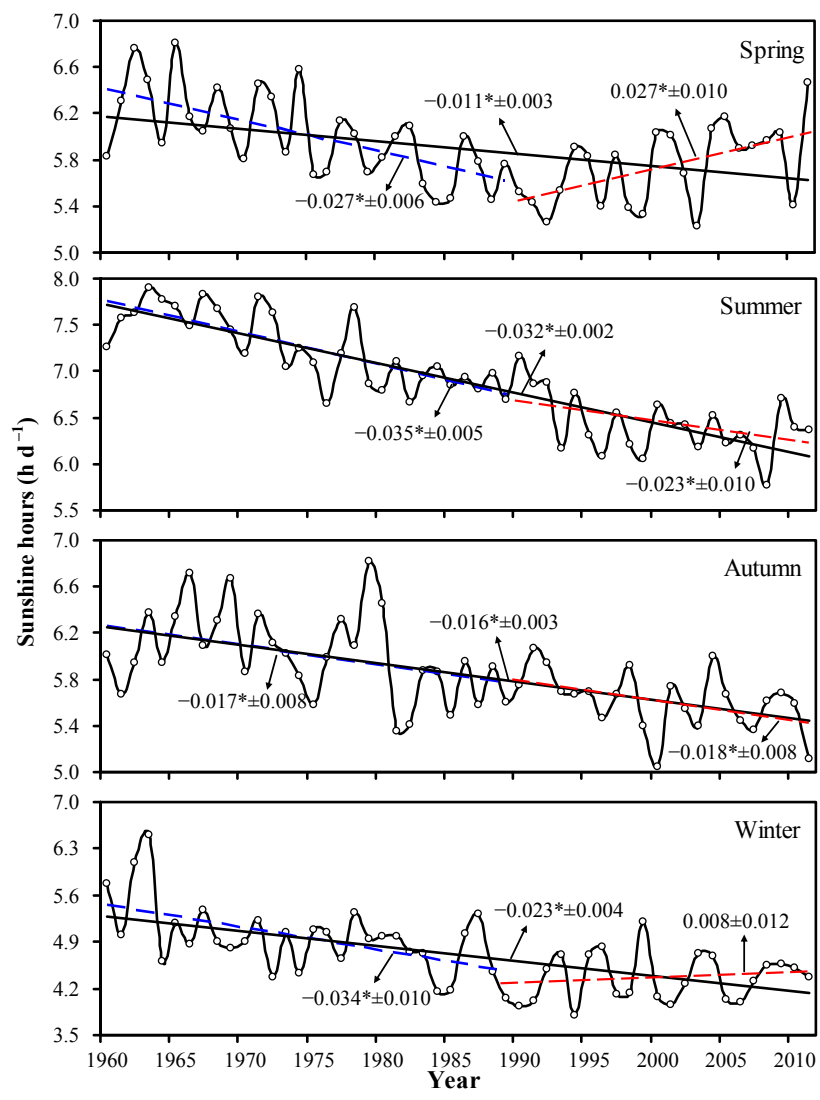

Fig. 4. Time series of seasonally averaged daily sunshine hours of 42 cites across China for the period 1960-2011. Black solid line, blue and red dash lines respectively denote linear trend for the periods 1960-2011, 1960-1989 (dimming phase) and 1990-2011 (brightening phase). Values denote trend slopes and corresponding standard errors, and $*$ is significant trend at the $95 \%$ confidence level.

\section{Causes of dimming and brightening in China}

\subsection{Cloud radiative forcing}

By reflecting incoming solar radiation back into space, clouds have been identified as a major modulator of SSR (Dessler, 2010). SSR and clouds show opposite trends, implying that increasing clouds result in decreasing SSR and vice versa (Wang et al., 2011). In general, there are two opposing views on the contribution of clouds to the variations in SSR and SH in China.

Opponents believe that clouds could not be the dominant driving factor of dimming and brightening in China as the total cloud cover (TCC) trend is very similar to the SSR trend (Liang and Xia, 2005; Xia et al., 2006; Yang et al., 2007; Shen et al., 2008). In Table 3, a positive correlation (with coefficient of 0.23 ) is noted between $\mathrm{SH}$ and TCC over the whole of China for the period 1955-2005 (Xia, 2012b). Slight increase in low cloud cover (LCC), which is linked to enhanced aerosol concentrations throughout the troposphere and lower stratosphere, could have caused the decrease in SSR and SH in China (Ren et al., 2005; Xia, 2010b; Zhao et al., 2010; Ma et al., 2011). Negative correlations between LCC and SSR/SH are noted in different parts and even entirely across China in recent decades (Table 3 ). Furthermore, some observations, such as more frequent and stronger dimming in cloud-free skies (Qian et al., 2006, 2007) and urban regions ( $\mathrm{Li}$ et al., 2012; Wang et al., 2013), lend credence to the explanation for increasing anthropogenic aerosols. By comparing annual trends in $\mathrm{SH}$ and TCC between 42 cities and 42 nearby counties, Wang et al. (2013) noted a widening gap between SH trends since 1978 while TCC remained fairly unchanged. This finding further confirmed that changes in SH in China are not driven by regional-based TCC.

In contrast, proponents assert that half of the decadal SSR variability after 1990 should be attributed to changes in TCC (Norris and Wild, 2009; Xia, 2010a; Wang et al., 2011). Furthermore, the effect of clouds on SSR and SH is significant in specific regions. Xia (2010a) asserted that despite the negligible effect of TCC to the trend in SSR over the whole of China, TCC to some extent changes in response to dimming in northwestern and southeastern China. Tang et al. (2011) and Yang et al. (2012a) confirmed that the importance of cloud effect to changes in solar radiation over the Tibetan Plateau could be comparable to that of aerosol effect. In Table 3, a significant negative correlation exists between radiation and cloud cover in different regions of southern China (Wang et al., 2010; Li et al., 2011; Zheng et al., 2011; Li et al., 2012). Actually, clouds significantly impact radiation at daily to inter-annual timescales (Norris and Wild, 2009; Xia, 2010a, b). To completely characterize the effects of clouds on radiation requires a full understanding of the amount, type (low, middle and high) and physical and radiative properties (shape, size and optical thickness) of clouds (Liang and Xia, 2005; Qian et al., 2006; Xia, 2010b).

\subsection{Aerosol radiative forcing}

Aerosols are defined as solid or liquid particles suspended in the atmosphere with a diameter range of $0.001-100 \mu \mathrm{m}$. Atmospheric aerosols are basically of natural and anthropogenic origin and composite mixtures of core refractory materials such as black carbon (BC, from fossil fuel combustion and biomass burning), dust (from surface winds in arid/semiarid regions) and sea salt (from bursting bubbles over the sea) along with coatings of organics (from biomass burning), sulfates (from anthropogenic activities) and nitrates (from anthropogenic activities) (Ramanathan et al., 2001; Satheesh, 2012). As one of the largest developing countries in the world, rapid economic growth and population expansion in China have triggered increasing emissions of anthropogenic aerosols and the related precursors (Qian et al., 2006; Xia et al., 2007c). In principle, aerosols modify solar radiation through direct and indirect radiative 
Table 3. Correlation coefficients between radiative (SSR, surface solar radiation; SH, sunshine hours) and meteorological (TCC, total cloud cover; LCC, low cloud cover; WS, wind speed; VAP, water vapor pressure; RH, relative humidity; $P$, precipitation; $E_{\text {pan }}$, pan evaporation) variables.

\begin{tabular}{|c|c|c|c|c|c|c|c|c|c|c|c|}
\hline & Reference & Study area & $\begin{array}{c}\text { Number } \\
\text { of sites }\end{array}$ & Period & TCC & $\mathrm{LCC}$ & WS & VAP & RH & $P$ & $E_{\text {pan }}$ \\
\hline \multirow[t]{4}{*}{ SSR } & Qian et al. (2006) & Whole China & 85 & $1955-2000$ & & & & & & & $0.57^{\mathrm{c}}$ \\
\hline & Xu et al. (2006) & Whole China & 305 & $1969-2000$ & & & $0.714^{\mathrm{b}}$ & & & & \\
\hline & Wang et al. (2010) & Southeastern China & 85 & $1961-2008$ & $-0.488^{b}$ & $-0.727^{b}$ & & & & & \\
\hline & Zheng et al. (2011) & Yunnan-Guizhou Plateau & 8 & $1961-2005$ & $-0.880^{b}$ & & $0.237^{\mathrm{a}}$ & & $-0.526^{\mathrm{b}}$ & & \\
\hline \multirow[t]{11}{*}{$\mathrm{SH}$} & Ren and Guo (2006) & Whole China & 600 & $1956-2000$ & & & & & & & $0.75^{\mathrm{b}}$ \\
\hline & Du et al. (2007) & Tibet & 25 & $1971-2005$ & $-0.052^{\mathrm{c}}$ & $-0.373^{\mathrm{c}}$ & & $-0.749^{\mathrm{c}}$ & & $-0.522^{\mathrm{c}}$ & \\
\hline & Shen and Sheng (2008) & Whole China & 472 & $1957-2001$ & & & & & & & $0.61^{b}$ \\
\hline & Cong et al. (2009) & Whole China & 317 & $1956-2005$ & & & & & & & $0.75^{\mathrm{a}}$ \\
\hline & Yang et al. (2009a) & Northern China & 81 & 1965-1999 & & & $0.66^{\mathrm{b}}$ & & $-0.64^{\mathrm{b}}$ & $-0.48^{\mathrm{b}}$ & \\
\hline & Xia (2010b) & Whole China & 618 & $1955-2005$ & 0.23 & $-0.52^{\mathrm{a}}$ & & & & & \\
\hline & You et al. (2010) & Eastern and central Tibetan Plateau & 71 & $1961-2005$ & -0.07 & $-0.76^{\mathrm{a}}$ & & -0.65 & $-0.61^{\mathrm{a}}$ & $-0.51^{\mathrm{a}}$ & \\
\hline & Li et al. (2011) & Low-altitude belt of southern China & 147 & $1961-2005$ & $-0.47^{\mathrm{b}}$ & $-0.90^{\mathrm{b}}$ & & & & & \\
\hline & Yu et al. (2011) & Whole China & 194 & $1951-2009$ & & & $0.76^{\mathrm{b}}$ & & & $-0.27^{\mathrm{a}}$ & \\
\hline & Li et al. (2012) & Southwestern China & 111 & $1961-2009$ & $-0.34^{\mathrm{a}}$ & & $0.58^{\mathrm{a}}$ & & $-0.32^{\mathrm{a}}$ & $-0.29^{\mathrm{a}}$ & \\
\hline & Yang et al. (2012b) & Southwestern China & 110 & $1969-2009$ & & & $0.46^{\mathrm{a}}$ & & & & \\
\hline
\end{tabular}

forcings (Charlson et al., 1992; Ramanathan et al., 2001). Direct radiative forcing refers to the scattering (primarily by sulfate, nitrate, and organic carbon aerosols) and/or absorption (primarily by $\mathrm{BC}$ aerosols) of solar radiation by the nature of aerosol composition (IPCC, 2007; Myhre, 2009; Dwyer et al., 2010; Satheesh, 2012). Indirect radiative forcing is caused by aerosols acting as cloud condensation nuclei $(\mathrm{CNN})$ and ice nuclei, which in turn influence cloud radiative properties and lifetimes (Charlson et al., 1992; Ramanathan et al., 2001; IPCC, 2007). All the aerosol radiative forcings act towards reducing SSR and SH. Moreover, aerosols could have semi-direct radiative forcing by inhibiting cloud formation or dissolving existing clouds as absorbing aerosols in heavily polluted regions could heat up and stabilize the atmosphere (Wild, 2009). This could partially counteract aerosolinduced dimming in heavily polluted areas for reduced cloud shading (Wild, 2012a).

Aerosol radiative forcings over the inland areas of China were not quantified until the mid-2000s, when the East Asian Study of Tropospheric Aerosols: An International Regional Experiment (EAST-AIRE) commenced as a USAChina cooperative research endeavor ( $\mathrm{Li}$ et al., 2007a). It consists of two baseline observatories established at Xianghe and Taihu, a nationwide aerosol observation network covering 25 stations across China, and two consecutive IOCs (intensive observation campaigns) conducted in the spring of 2005. This was done in March on the ground in Xianghe and in April from both aircraft and ground in Liaozhong. The EAST-AIRE study primarily aims to acquire optical, physical and chemical properties of aerosols and to understand climatic and environmental effects of the aerosol properties. Quantification of aerosol radiative forcings has therefore been enabled by the simultaneous highquality observations of aerosol, cloud and radiative quantities made in the EAST-AIRE stations. At the Xianghe site (70 km southeast of Beijing), Li et al. (2007b) detected that high aerosol loading resulted in a very large aerosol radiative effect at the surface (the annual mean value equals $-24.1 \mathrm{~W} \mathrm{~m}^{-2}$ ) from September 2004 to September 2005; only moderately lower than the cloud radiative effect $\left(-41.0 \mathrm{~W} \mathrm{~m}^{-2}\right)$. At the Taihu site $(100 \mathrm{~km}$ west of Shanghai), Xia et al. (2007b) noted that heavy aerosol loading resulted in $-45.5 \mathrm{~W} \mathrm{~m}^{-2}$ and $-112.6 \mathrm{~W} \mathrm{~m}^{-2}$ reductions in SSR and DiSR while $67.1 \mathrm{~W} \mathrm{~m}^{-2}$ more DfSR reached Earth's surface from September 2005 to August 2006. The annual mean aerosol direct radiative forcing at the surface amounted to $-38.4 \mathrm{~W} \mathrm{~m}^{-2}$. At the Liaozhong site, a suburban region in northeastern China, Xia et al. (2007a) estimated that aerosols reduced SSR by $30 \mathrm{~W} \mathrm{~m}^{-2}$ day $^{-1}$ from April to June 2005.

Aerosol optical depth (AOD) and air pollution index (API) are the two widely used proxies for aerosols in air quality studies (Neha, 2000; He et al., 2002; Li et al., 2003, 2005; Pour-Biazar et al., 2011). AOD (also known as AOT, aerosol optical thickness) measures wavelength-dependent aerosol extinction in the atmospheric column via remote sensing (Bellouin et al., 2005). API is the generalized way of describing air quality in China, which is based on $24 \mathrm{~h}$ ground-based monitoring of mass concentration of three principal air pollutants $-\mathrm{SO}_{2}, \mathrm{NO}_{2}$, and $\mathrm{PM}_{10}$. API measurements started with a few stations in 2000 and since then has gradually expanded to 120 environmental monitoring stations, mainly in major cities of China (Fig. 1). These data are now available at the China National Environmental Monitoring Center (CNEMC, http://www.cnemc.cn/), which is managed by the State Environmental Protection Bureau (SEPB). Based on the Ambient Air Quality Standards, eco-environmental effects of various pollutants and their health implications, the API scale $(0$ 500) corresponds to seven air pollution levels - I (excellent, 0-50), II (good, 51-100), III(1) (slight pollution, 101-150), 


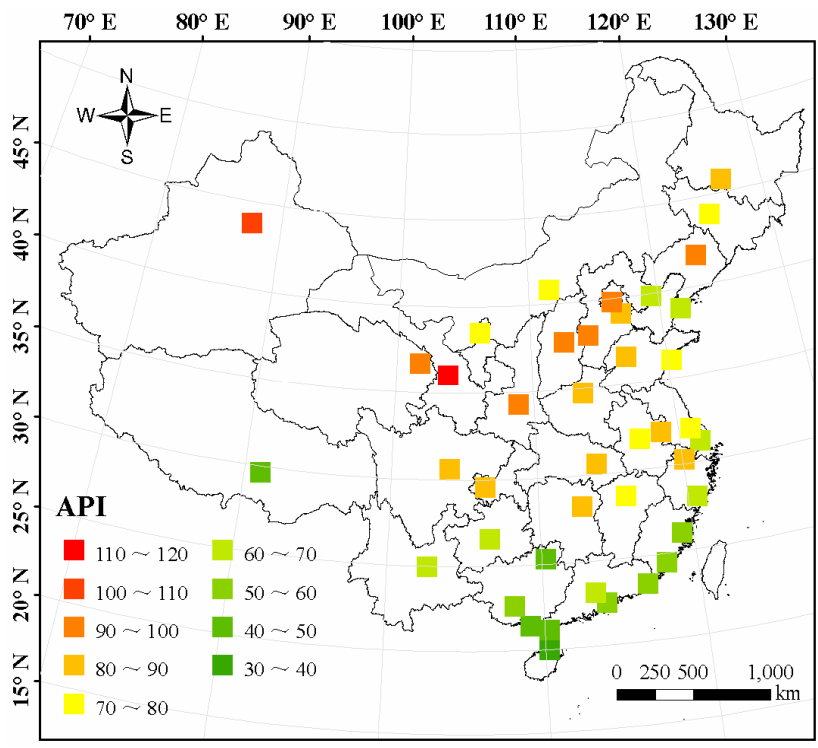

Fig. 5. Spatial distribution of average daily API over 42 cities across China for the period 2001-2011.

III(2) (light pollution, 151-200), IV(1) (moderate pollution, 201-250), IV(2) (heavy pollution, 251-300), and V (severe pollution, 300+). Wang et al. (2012) have proved the value of API as a separate indicator in studying the influence of air pollution on SH. In Fig. 5, a boundary line $\left(30^{\circ} \mathrm{N}\right)$ is drawn for air quality conditions in China. To the north of the line where solar dimming continues after 1990, average API in the 2000s is generally greater than 70 . To the south of the line where brightening occurs air quality is relatively good. Wang et al. (2012) verified that in cities with average API $>80$, the SH decline for the $1960 \mathrm{~s}-2000 \mathrm{~s}$ is $0.2 \mathrm{~h} \mathrm{~d}^{-1}(2.5 \%)$ stronger than in cities with average daily $\mathrm{API} \leq 80$. Ground observed API and remotely sensed AOD are noted to be strongly correlated after correction for aerosol seasonal vertical distribution and real-time relative humidity (Li et al., 2003; He et al., 2010). The correlation coefficient between AOD and API could improve to 0.54 at $99 \%$ confidence level (Li et al., 2005).

Figure 2d shows a sharp increase in AOD (simulated using the GOCART model) over China in the 1980s (Streets et al., 2008), the decade with the strongest decline in SSR and SH during the last half century. An increase in AOD is especially notable in the middle and lower reaches of Yangtze River and the southern coastal areas (Luo et al., 2000, 2001, 2002; Lu and Fang, 2002), where strong dimming is prevalent. AOD increases to a peak value of 0.305 in 1996 and declines thereafter (Fig. 2d), corresponding to the transition from dimming to brightening in SSR and SH trends. Following that is an almost linear decline in average API in the period 2001-2011 (Fig. 2d), especially in spring (Wang et al., 2013), which is consistent with annual and seasonal brightening trends. Similar observations were made by Lei et al. (2011a) and Wang et al. (2012a) for $\mathrm{PM}_{2.5}$ concentration, which better determines AOD than $\mathrm{PM}_{10}$. Due, however, to the complexity of the composition and mixing of aerosols and the subsequent scattering/absorption of SSR (Qian et al., 2006, 2007), a simple correlation could hardly be established between API and SH at an annual scale. Using TOMS AOD products (1980-2001) along with MODIS/Terra AOD data (2000-2008), Guo et al. (2011) noted a continuous upward trend in average AOD $(550 \mathrm{~nm})$ over eight typical regions across China without any transition in 1990. This is contrary to recent brightening or leveling off trends in SSR and SH. Nevertheless, earlier declines in carbonaceous aerosol emissions than in sulfur dioxide emissions reported over East Asia imply changing patterns in anthropogenic emissions (Streets et al., 2006, 2008). Increasing aerosol single scattering albedo (SSA, which is the ratio of scattering to extinction) could result in less absorption and thus more radiation reaching Earth's surface (Qian et al., 2007). Aerosols not only change the amount of SSR but also alter the partitioning between direct and diffuse components of SSR for distinct chemical compounds (Xia et al., 2007c).

Except for human activities, volcanic eruptions such as in El Chichon (1982) and the Philippine's Mount Pinatubo (1991) also strongly perturb the Earth-atmosphere system (Qiu and Yang, 2000; Wild, 2009). In the broad northwest of China and in the months from March to May, dust storms significantly impact solar radiation (X. Wang et al., 2004; Shen et al., 2011).

\subsection{Wind speed}

It is worth noting that in spite of the two principal driving factors (cloud and aerosol), wind also significantly influences SSR and SH. Xu et al. (2006) detected that annual mean wind speed and surface incoming solar radiation share similar decadal trends in China. A significantly positive correlation between SSR and WS was also noted by Zheng et al. (2011) in the Yunnan-Guizhou Plateau. Among various meteorological parameters, wind speed is most closely correlated with SH in northern China (Yang et al., 2009a), southwestern China (Li et al., 2012; Yang et al., 2012b) and the whole of China (Yu et al., 2011). Corresponding coefficients of the observed correlations between SSR/SH and WS are shown in Table 3. Winds could disperse and alter the frequency and distribution of air pollutants and aerosol derivatives, thereby indirectly influencing SH and SSR (Lu and Fang, 2002; Xu et al., 2006; Yang et al., 2009b; Li et al., 2012). In Fig. 5, cities with relatively good air quality are mainly distributed in the high monsoon wind regions, especially in the tropical and subtropical monsoon climate zone (southeastern China). For the past $50 \mathrm{yr}$, mean annual wind speed significantly declines at the rate of $0.1 \mathrm{~m} \mathrm{~s}^{-1}$ decade $^{-1}$ in China. This is attributed to the weakening East Asian monsoon and windbreak effect of the high-rise buildings, which are quickly constructed in China's urbanization boom (Z. Wang et al., 2004; Ren et al., 
2005; Zuo et al., 2005; Xu et al., 2006; Cong et al., 2009; Liu et al., 2009; Yin et al., 2010). Wind deceleration could enhance aerosol concentration in the atmosphere, which in turn dims SSR and SH in China (Zhao et al., 2010; Yang and Yang, 2012).

\subsection{Other potential driving factors}

Other variables also exert non-negligible influences on SSR and SH. Despite air pollution, change in surface albedo, which is also associated with urbanization, has a negative radiative forcing. Human activities are altering the nature of land cover, especially through changes in croplands, pastures and forests, resulting in more reflection of solar radiation from Earth's surface (IPCC, 2007). So far, however, large uncertainties remain in the contributions of changes in surface albedo to China's dimming and brightening.

Water vapor is a strong absorber of solar radiation; i.e., a $10 \%$ increase in water vapor attenuates solar radiation by up to $0.5 \%$ (Wild, 2009). Wang et al. (2011) showed that SSR negatively correlates with near-surface water vapor in most regions of China, especially in relatively dry high-latitude regions. For instance, in the Tibetan Plateau, a higher correlation was noted by Du et al. (2007) and You et al. (2010) between SH and water vapor pressure than with other meteorological variables (Table 3). This suggests that the effect of water vapor on solar radiation largely depends on the background level of water vapor content. Similar variables with different measurements are relative humidity and precipitation. The interaction of relative humidity and aerosols influences the development of cloudy conditions (Wang et al., 2012). Precipitation could wash out aerosols and reduce the amount of clouds, which in turn mitigate the effect of aerosols and clouds on SSR and SH (Ramanathan et al., 2001). Table 3 shows that relative humidity and precipitation have a significant negative correlation with SSR/SH in various regions of China (Yu et al., 2011; Zheng et al., 2011; Yang et al., 2012b), especially in the Tibetan Plateau (Du et al., 2007; You et al., 2010) and northern China (Yang et al., 2009a).

\section{Hydrological implications of dimming and brightening in China}

\subsection{Link between radiation balance and hydrological cycle}

Since the process of evaporation requires energy (e.g., latent heat), solar radiation is the principal driver of the global hydrological cycle (Wild and Liepert, 2010). Decreasing SSR (i.e., global dimming) could attenuate latent heat of evaporation and the equivalent global precipitation, thereby spinning down the hydrological cycle. On the other hand, increasing SSR (i.e., global brightening) could induce stronger latent heat of evaporation and more frequent rainfall, thereby spinning up the hydrological cycle (Ramanathan et al., 2001; Wild, 2009, 2012a, b).

\subsection{Implications for pan evaporation}

Pan evaporation $\left(E_{\mathrm{pan}}\right)$, the most widely used proxy for potential evaporation, measures evaporation in a standard open pan of water (Wild, 2009). Basically, the potential factors that influence $E_{\mathrm{pan}}$ can be divided into three category terms: thermodynamic term (temperature, sunshine hours and diurnal temperature range), aerodynamic term (wind speed and pressure) and hydrodynamic term (relative humidity, precipitation and low cloud cover) (Liu et al., 2009; Shen et al., 2010). Peterson et al. (1995) attributed the general decline in $E_{\mathrm{pan}}$ in the United States and the former Soviet Union for the period 1950-1990 to increasing cloudiness. In subsequent studies, Brutsaert and Parlange (1998) proposed that the observed decline in $E_{\text {pan }}$, which indicated increasing terrestrial evaporation, should not be a paradox. Ohumura and Wild (2002) argued that the direction of the $E_{\mathrm{pan}}$ trend is not determined by temperature alone. Rayner (2007) identified wind run (i.e., daily average wind speed) as the dominant factor of $E_{\mathrm{pan}}$ trends in Australia. Roderick and Farquhar (2002) theorized the resolution of the pan evaporation paradox by explaining how a downward $E_{\text {pan }}$ trend could be driven by global dimming. The fact that SSR and $E_{\text {pan }}$ trends in China have a similar transition in 1990 (Liu et al., 2004; Qian et al., 2006) is further evidence that solar radiation dominantly controls the recent $E_{\text {pan }}$ trend.

Figure 2c shows a significant decline in $E_{\text {pan }}$ by $54 \mathrm{~mm}$ decade $^{-1}$ in China's dimming phase (Liu et al., 2011a), suggesting that solar dimming offsets the effect of increasing air temperature on $E_{\mathrm{pan}}$. The decline in $E_{\mathrm{pan}}$ is strongest in summer (Ren and Guo, 2006; Liu et al., 2009; Shen and Sheng, 2009) and in regions around southeastern China and the middle and lower reaches of Yangtze River (Yan et al., 2007; Shen and Sheng, 2008; Liu et al., 2009). This corresponds with seasonal and spatial trends in dimming of SSR and SH. The mean annual $E_{\text {pan }}$ in China has significantly increased by $79 \mathrm{~mm}$ decade $^{-1}$ since 1992 (Liu et al., 2011a), consistent with the recovery of solar radiation in the country (Fig. 2). For the period since the mid-1950s, the $E_{\mathrm{pan}}$ trend is significantly and positively correlated with the SSR/SH trend in China (Table 3), with an estimated coefficient $\geq 0.57$ (Qian et al., 2006; Ren and Guo, 2006; Shen and Sheng, 2008; Cong et al., 2009).

According to Cong et al. $(2009,2010), E_{\text {pan }}$ increases in the north while continues to decrease in the south after 1986; in discordance with the spatial pattern of solar brightening. This suggests that other factors other than solar radiation also influence $E_{\mathrm{pan}}$. Cong et al. (2009) and Liu et al. (2011a) reckoned that increasing $E_{\text {pan }}$ since the 1990 s is caused by decreasing vapor pressure deficit due to strong warming. Water conditions in different climatic regions and seasons influence the sensitivity of $E_{\mathrm{pan}}$ to changes in solar radiation (Liu 
et al., 2004). Besides this, wind speed is widely regarded as another important driving factor of the pan evaporation paradox in China (Ren et al., 2005; Ren and Guo, 2006; Cong et al., 2009; Liu et al., 2011a). Shen and Sheng (2008, 2009) asserted that thermodynamic and aerodynamic terms respectively dominate the drop of $E_{\mathrm{pan}}$ in eastern and western China.

\section{Key regions}

Southeastern China is the region with the most obvious dimming and brightening for the periods 1960s-1980s and 1990s-2000s, respectively (Ohmura, 2006; Xia, 2010a; Wild and Schmucki, 2011; Wang et al., 2012). The prevailing climate in the region is tropical and subtropical monsoon with frequent cloud events, heavy rainfall and strong sunshine. Since the implementation of the reform and openingup policy in 1978, this region has experienced fast economic growth that has in turn led to a drastic increase in AOD (Luo et al., 2000, 2001, 2002; Lu and Fang, 2002). Li et al. (2011) showed that increased aerosol loading due to rapid socio-economic development is the driving force behind the sharp dimming in this region. The latter brightening trend might be in response to improved air quality. As illustrated in Fig. 5, the average API level in southeastern China is generally lower than 70 for the 2000s. Aerosol-linked LCC has been identified as the primary meteorological regulator of SSR and SH in this region (Wang et al., 2010; Li et al., 2011). The strongest dimming rate in southeastern China, however, was not in phase with the highest $E_{\mathrm{pan}}$ decrease in the period 1955-2000. This suggests that plentiful water conditions reduced the sensitivity of $E_{\text {pan }}$ to change with SSR (Liu et al., 2004).

Continued dimming since 1990 is prevalent in northern China (Ohmura, 2006; Yang et al., 2007; Xia, 2010a; Wang et al., 2011, 2013). This region is dominated by the East Asian monsoon climate of hot, humid, low-latitude western Pacific winds in summer, and cold, dry Siberian winds in winter. Increased aerosol emissions driven by air pollution have been identified by Yang et al. (2009b) as the cause of dimming in this region. In Fig. 5, a relatively high level of API could be noted. Through interaction with aerosol loading, wind speed exerts the strongest influence on SH in northern China (Yang et al., 2009a). Wind speed, rather than SSR, is also the dominant factor for decreasing $E_{\mathrm{pan}}$ in this region from 1960 to the early 1990s (Liu et al., 2011a). A significant wind effect is also observed in southwestern China (Li et al., 2012; Yang et al., 2012b), which is a typical monsoonal climate region dominated by both the South and East Asian monsoon winds. The pan evaporation paradox is not existent in southwestern China, as $E_{\text {pan }}$ decreases with decreasing air temperature (Cong et al., 2009).

The smallest mean AOD in China is for the Tibetan Plateau region (Xin et al., 2007). Aerosol effect on dimming and brightening in this region is still under debate. You et al. (2013) suggested that aerosol is the determinant factor of SSR in the Tibetan Plateau. This view is supported by the fact that aerosol loading is impacted by the long-range transportation of anthropogenic aerosols from southern Asia (Xia et al., 2011) and dust aerosols from the Taklimakan Desert (Xia et al., 2008) to the region. However, Yang et al. (2012a) argued that under low water vapor content and aerosol concentration in the plateau, water vapor amount and deep cloud cover become the dominant driving factors of SSR. In fact, water vapor has been verified as a critical regulator of SSR in regions at high latitudes with dry atmosphere, such as in northeastern and northwestern China (Wang et al., 2011). The water deficit in northwestern China also increases the sensitivity of $E_{\mathrm{pan}}$ to change in SSR, thus the rate of decrease in $E_{\mathrm{pan}}$ is highest in the region (Liu et al., 2004). The pan evaporation paradox does not exist in northeastern China, because $E_{\text {pan }}$ increases with the increasingly warmer climate (Cong et al., 2009). The dominant climatic factor of the decreasing $E_{\mathrm{pan}}$ trend in the Tibetan Plateau for the period 1970-2005 is wind speed, followed by vapor pressure and SSR (Liu et al., 2011b).

\section{Discussions and suggestions for future research}

It is undisputed that since the 1950 s, solar radiation over China suffers a temporally and spatially prevalent decreasing trend. However, the magnitude of China's dimming estimated in recent studies differs greatly (Che et al., 2005; Shi et al., 2008; Norris and Wild, 2009; Ohmura, 2009; Wang et al., 2009; Tang et al., 2011; Wild, 2012a). There is no concordance in conclusions on the seasonal dimming trends in SSR (Shi et al., 2008; Wang et al., 2009; Xia, 2010a) and DiSR (Zhao et al., 2009; Ma et al., 2011). By contrast, results of estimated SH trends are largely in agreement (Xia, 2010b; Zhao et al., 2010; Yu et al., 2011). The uncertainties in solar radiation studies highlight the importance of data quality assessment and control, as erroneous and suspected data could lead to unreliable and spurious trends. Distinct data sets with varied spatial coverage and timescales could also influence the consistency of results. In addition, more accurate, higherorder statistical models rather than current linear regressions are needed in trend analysis (Wild, 2009). There is an overwhelming scientific consensus that increasing anthropogenic aerosol loading is the most plausible explanation for China's dimming (Kaiser and Qian, 2002; Che et al., 2005; Qian et al., 2006, 2007; Wen et al., 2008; Xia, 2010b). This is further confirmed by the decreasing trend in TCC (Liang and Xia, 2005; Xia et al., 2006; Yang et al., 2007; Shen et al., 2008), although cloud changes to some extent account for the dimming in the Tibetan Plateau (Tang et al., 2011; Yang et al., 2012a), northwestern China (Xia, 2010a) and most of southern China (Wang et al., 2010; Li et al., 2011; Zheng et al., 2011; Li et al., 2012) (Table 3). A higher dimming rate in 
urban regions than in rural regions also reflects the attenuation effect of urbanization-induced air pollution on sunlight (Li et al., 2012; Wang et al., 2013). So far, proof of aerosol as the prime regulator of China's dimming largely depends on simple trend comparisons and is insufficient from physical mechanisms.

The solar radiation trend after 1990 , however, largely remains debatable in China. The latest updates presented that the recent trend in SSR (Tang et al., 2011) and SH (Wang et al., 2013) levels off rather than brightening. At a global scale, brightening mainly occurs in industrialized regions, accompanying a slowdown in anthropogenic emissions and economic growth (Wild, 2009, 2012a). Similarly, there was improvement of air quality in China in the early 21 st century (Chen et al., 2010; Shaw et al., 2010; Lei et al., 2011b; Wang et al., 2012, 2013). In fact, a tremendous effort is applied to sustain economic development and intensive environmental protection since the start of China's environmental protection in the 1970s. Such effort is especially commendable after the 1992 act of sustainable development as a standard national strategy (Zhang and Wen, 2008). As one of the largest developing countries, China is still in the period of rapid economic growth and population expansion. The possibility for renewed dimming cannot be excluded and has already been discussed in studies of Che et al. (2005) and Wild et al. (2009). It can then be predicted that the future solar radiation trend in China could largely depend on the development of air quality control. On the other hand, the possible influence of climate-driven TCC suppression on solar recovery after 1990 is non-negligible (Norris and Wild, 2009; Xia, 2010a; Wang et al., 2011). The reversal in SSR and SH trends could be associated with natural and anthropogenic factors. Being that other radiation factors such as DiSR, DfSR and photosynthetically active radiation (RAR) are noted to have different environmental implications (Che et al., 2005; Pinker et al., 2005; Zhu et al., 2010), there is a need for systematic studies on these SSR components.

Although wind hardly actually changes emission trends and pollutant sources, the transport of air pollutants is predominantly controlled by wind speed. In other words, winds partially determine the residence time, distribution pattern and pollutant/aerosol concentration in the atmosphere. So far, there is no conclusive evidence on the effect of wind speed on SSR and SH under varying air pollution levels. Wind acceleration could lead to dispersion of aerosols in the source regions, but accumulation of aerosols in the downwind regions. Furthermore, increasing wind speed in the desert and Gobi regions could result in more dust aerosols emitted into the atmosphere, which in turn attenuates sunlight. This calls for further research on wind speed as a critical driving factor of solar radiation to help better understand the cause-effect relationship between air pollution and solar dimming.

The effects of other potential driving factors (water vapor and surface albedo) on SSR and SH are also nonnegligible in specific conditions. For instance, in western arid/semi-arid regions of China where the atmosphere is relatively dry, the weakening function of water vapor (relative humidity/precipitation) on sunlight is evident (Du et al., 2007; You et al., 2010; Wang et al., 2011) (Table 3). In areas with sustained and intensive human activities, radiative forcing of surface albedo needs consideration.

Research on hydrological implications of dimming and brightening in China is only in its infancy. Despite evaporation, the implications for other hydrological components such as precipitation have seldom been studied in China. Similar to the analyses of the causes of solar dimming and brightening in China, hydrological implications tend to very much rely on trend comparisons rather than critical interpretations of physical mechanisms. The main scientific process is that, similar to the solar radiation trend, the $E_{\mathrm{pan}}$ trend in China reverses from decreasing to increasing in 1990 (Liu et al., 2004; Qian et al., 2006). This evidence further confirms the claim that the pan evaporation paradox could be resolved by solar dimming (Roderick and Farquhar, 2002). Comparing the dimming phases in Fig. 2a and c, a decline of $2.5 \mathrm{~W} \mathrm{~m}^{-2}$ decade $^{-1}$ in SSR is accompanied by a $54 \mathrm{~mm}$ decade $^{-1}$ decline in pan evaporation. For the brightening phase, an increase of $0.4 \mathrm{~W} \mathrm{~m}^{-2}$ decade $^{-1}$ in SSR is accompanied by $79 \mathrm{~mm}$ decade ${ }^{-1}$ increase in pan evaporation. This suggests that to some extent, solar dimming, but also decreasing wind speed, offsets the effect of warming climate on evaporation. This in turn results in a decline in pan evaporation. On the contrast, strong warming with a slight increase in solar radiation leads to a more significant recovery in pan evaporation for the brightening phase (Liu et al., 2011a; Wild, 2012a). Assuming that solar dimming and brightening in China are largely driven by anthropogenic aerosols with possible effects on pan evaporation, hydrological observations and simulations of evaporation could be skewed by air pollution. This aspect of pollution-driven hydrological processes requires intensive scientific studies for a conclusive clarification. More scientific works are required to unveil the hydrological implications of solar dimming and brightening in China.

Acknowledgements. This study is funded by the International Collaborative Project (2012DFG90290) of the Ministry of Science and Technology and the Basic Research Development Program of China (2010CB951002). The meteorological and solar radiation data are provided by China National Meteorological Information Center (CNMIC). API data are from China National Environmental Monitoring Center (CNEMC). The authors are thankful to Prof. Paolo Michele Ruti and two anonymous reviewers for the invaluable suggestions and comments during the review phase of this paper.

Topical Editor P. M. Ruti thanks X. Xia and one anonymous referee for their help in evaluating this paper. 


\section{References}

Alpert, P., Kishcha, P., Kaufman, Y. J., and Schwarzbard, R.: Global dimming or local dimming?: Effect of urbanization on sunlight availability, Geophys. Res. Lett., 32, L17802, doi:10.1029/2005GL023320, 2005.

Angell, J. K. and Korshover, J.: Recent increase in sunshine duration within contiguous Uinted-States, J. Appl. Meteorol., 17, 819-824, 1978.

Bellouin, N., Boucher, O., Haywood, J., and Reddy, M. S.: Global estimate of aerosol direct radiative forcing from satellite measurements, Nature, 438, 1138-1141, 2005.

Brutsaert, W. and Parlange, M. B.: Hydrologic cycle explains the evaporation paradox, Nature, 396, 30, doi:10.1038/23845, 1998.

Charlson, R. J., Schwartz, S. E., Hales, J. M., Cess, R. D., Coakley, J. A., Hansen, J. E., and Hofmann, D. J.: Climate forcing by anthropogenic aerosols, Science, 255, 423-430, 1992.

Chattopadhyay, N. and Hulme, M.: Evaporation and potential evapotranspiration in India under conditions of recent and future climate change, Agr. Forest Meteorol., 87, 55-73, 1997.

Che, H. Z., Shi, G. Y., Zhang, X. Y., Arimoto, R., Zhao, J. Q., Xu, L., Wang, B., and Chen, Z. H.: Analysis of 40 years of solar radiation data from China, 1961-2000, Geophys. Res. Lett., 32, L06803, doi:10.1029/2004GL022322, 2005.

Chen, S., Zhang, K., Xing, X., and Dong, A.: Climatic change of sunshine duration in Northwest China during the last 47 years, Journal of Natural Resources, 25, 1142-1152, 2010.

Cong, Z. T., Yang, D. W., and Ni, G. H.: Does evaporation paradox exist in China?, Hydrol. Earth Syst. Sci., 13, 357-366, doi:10.5194/hess-13-357-2009, 2009.

Cong, Z., Zhao, J., Yang, D., and Ni, G.: Understanding the hydrological trends of river basins in China, J. Hydrol., 388, 350-356, 2010.

Dessler, A. E.: A determination of the cloud feedback from climate variations over the past decade, Science, 330, 1523-1527, 2010.

Du, J., Bian, D., Hu, J., Liao, J., and Zhou, M. J.: Climatic change of sunshine duration and its influencing factors over Tibet during the last 35 years, Acta Geographica Sinica, 62, 492-500, 2007.

Dwyer, J. G., Norris, J. R., and Ruckstuhl, C.: Do climate models reproduce observed solar dimming and brightening over China and Japan?, J. Geophys. Res., 115, D00K08, doi:10.1029/2009JD012945, 2010.

Gilgen, H., Roesch, A., Wild, M., and Ohmura, A.: Decadal changes in shortwave irradiance at the surface in the period from 1960 to 2000 estimated from Global Energy Balance Archive Data, J. Geophys. Res., 114, D00D08, doi:10.1029/2008JD011383, 2009.

Guo, J. P., Zhang, X. Y., Wu, Y. R., Zhaxi, Y. Z., Che, H. Z., La, B., Wang, W., and Li, X. W.: Spatio-temporal variation trends of satellite-based aerosol optical depth in China during 1980-2008, Atmos. Environ., 45, 6802-6811, 2011.

He, K., Huo, H., and Zhang, Q.: Urban air pollution in China: Current status, characteristics, and progress, Annu. Rev. Energ. Env., 27, 397-431, 2002.

He, X., Deng, Z. Z., Li, C. C., Liu, Q. H., Wang, M. H., Liu, X. Y., and Mao, J. T.: Application of MODIS AOD in Surface PM $_{10}$ Evaluation, Acta Scientiarum Naturalium Universitatis Pekinensis, 46, 178-184, 2010.
Hoyt, D. V. and Schatten, K. H.: A discussion of plausible solar irradiance variations, 1700-1992, J. Geophys. Res.-Space Phys., 98, 18895-18906, 1993.

IPCC: Climate change 2007: The physical science basis, in: Contribution of Working Group 1 to the Fourth Assessment Report of the Intergovernmental Panel on Climate Change, edited by: Solomon, S., Qin, D., Manning, M., Chen, Z., Marquis, M., Averyt, K. B., Tignor, M., and Miller, H. L., Cambridge University Press, Cambridge, United Kingdom and New York, NY, USA, 2007.

Kaiser, D. P. and Qian, Y.: Decreasing trends in sunshine duration over China for 1954-1998: Indication of increased haze pollution?, Geophys. Res. Lett., 29, 2042, doi:10.1029/2002GL016057, 2002.

Lei, Y., Zhang, Q., He, K. B., and Streets, D. G.: Primary anthropogenic aerosol emission trends for China, 1990-2005, Atmos. Chem. Phys., 11, 931-954, doi:10.5194/acp-11-931-2011, 2011a.

Lei, Y., Zhang, Q., Nielsen, C., and He, K.: An inventory of primary air pollutants and $\mathrm{CO}_{2}$ emissions from cement production in China, 1990-2020, Atmos. Environ., 45, 147-154, 2011 b.

Li, C. C., Mao, J. T., Lau, A. K. H., Liu, X. Y., Liu, G. Q., and Zhu, A. H.: Research on the air pollution in Beijing and its surroundings with MODIS AOD products, Chinese J. Atmos. Sci., 27, 869-880, 2003.

Li, C. C., Mao, J. T., Lau, A. K. H., Yuan, Z. B., Wang, M. H., and Liu, X. Y.: Application of MODIS satellite products to the air pollution research in Beijing, Sci. China Ser. D-Earth Sci., 48, 209-219, 2005.

Li, W., Hou, M., and Xin, J.: Low-cloud and sunshine duration in the low-latitude belt of South China for the period 1961-2005, Theor. Appl. Climatol., 104, 473-478, 2011.

Li, Z., Chen, H., Cribb, M., Dickerson, R., Holben, B., Li, C., Lu, D., Luo, Y., Maring, H., and Shi, G.: Preface to special section on East Asian Studies of Tropospheric Aerosols: An International Regional Experiment (EAST-AIRE), J. Geophys. Res.-Atmos., 112, D22S00, doi:10.1029/2007JD008853, 2007a.

Li, Z., Xia, X., Cribb, M., Mi, W., Holben, B., Wang, P., Chen, H., Tsay, S. C., Eck, T., and Zhao, F.: Aerosol optical properties and their radiative effects in northern China, J. Geophys. Res.Atmos., 112, D22S01, doi:10.1029/2006JD007382, 2007b.

Li, Z., Feng, Q., Zhang, W., He, Y., Wang, X., Norm, C., An, W., Du, J., Chen, A., Liu, L., and Hu, M.: Decreasing trend of sunshine hours and related driving forces in Southwestern China, Theor. Appl. Climatol., 109, 305-321, 2012.

Liang, F. and Xia, X. A.: Long-term trends in solar radiation and the associated climatic factors over China for 1961-2000, Ann. Geophys., 23, 2425-2432, doi:10.5194/angeo-23-2425-2005, 2005.

Liu, B. H., Xu, M., Henderson, M., and Gong, W. G.: A spatial analysis of pan evaporation trends in China, 1955-2000, J. Geophys. Res.-Atmos., 109, D15102, doi:10.1029/2004JD004511, 2004.

Liu, M., Shen, Y., Zeng, Y., and Liu, C.: Changing trend of pan evaporation and its cause over the past 50 years in China, Acta Geographica Sinica, 64, 259-269, 2009.

Liu, X., Luo, Y., Zhang, D., Zhang, M., and Liu, C.: Recent changes in pan-evaporation dynamics in China, Geophys. Res. Lett., 38, L13404, doi:10.1029/2011GL047929, 2011 a. 
Liu, X., Zheng, H., Zhang, M., and Liu, C.: Identification of dominant climate factor for pan evaporation trend in the Tibetan Plateau, J. Geogr. Sci., 21, 594-608, 2011b.

Lu, H. and Fang, G.: Estimating the frequency distributions of PM10 and PM2.5 by the statistics of wind speed at Sha-Lu, Taiwan, Sci. Total. Environ., 298, 119-130, 2002.

Luo, Y., Lü, D., He, Q., Li, W., and Zhou, X.: Characteristics of atmospheric aerosol optical depth variation over China in recent 30 years, Chinese Sci. Bull., 45, 1328-1334, 2000.

Luo, Y., Lu, D., Zhou, X., Li, W., and He, Q.: Characteristics of the spatial distribution and yearly variation of aerosol optical depth over China in last 30 years, J. Geophys. Res., 106, 14501-14513, 2001.

Luo, Y., Lu, D., Zhou, X., and Li, W.: Analyses on the spatial distribution of aerosol optical depth over China in recent 30 years, Scientia Atmospherica Sinica, 26, 721-730, 2002.

Ma, J., Liang, H., Luo, Y., and Li, S.: Variation trend of direct and diffuse radiation in China over recent 50 years, Acta Phys. Sin., 60, 1-14, 2011.

Ma, J., Luo, Y., Liang, H., and Li, S.: Spatial and temporal variation of total solar radiation in China in recent 50 Years, Journal of Natural Resources, 27, 268-280, 2012.

Myhre, G.: Consistency between satellite-derived and modeled estimates of the direct aerosol effect, Science, 325, 187-190, 2009.

Neha, K.: Measuring environmental quality: An index of pollution, Ecol. Econ., 35, 191-202, 2000.

Norris, J. R. and Wild, M.: Trends in aerosol radiative effects over China and Japan inferred from observed cloud cover, solar "dimming", and solar "brightening", J. Geophys. Res., 114, D00D15, doi:10.1029/2008JD011290, 2009.

Ohmura, A.: Observed long-term variations of solar irradiance at the Earth's surface, Space Sci. Rev., 125, 111-128, doi:10.1007/s11214-006-9050-9, 2006.

Ohmura, A.: Observed decadal variations in surface solar radiation and their causes, J. Geophys. Res., 114, D00D05, doi:10.1029/2008JD011290, 2009.

Ohmura, A. and Wild, M.: Is the hydrological cycle accelerating?, Science, 298, 1345-1346, 2002.

Peterson, T. C., Golubev, V. S., and Groisman, P. Y.: Evaporation losing its strength, Nature, 377, 687-688, 1995.

Pinker, R. T., Zhang, B., and Dutton, E. G.: Do satellites detect trends in surface solar radiation?, Science, 308, 850-854, 2005.

Pour-Biazar, A., Khan, M., Wang, L., Park, Y. H., Newchurch, M., McNider, R. T., Liu, X., Byun, D. W., and Cameron, R.: Utilization of satellite observation of ozone and aerosols in providing initial and boundary condition for regional air quality studies, J. Geophys. Res.-Atmos., 116, D18309, doi:10.1029/2010JD015200, 2011.

Qian, Y., Kaiser, D. P., Leung, L. R., and Xu, M.: More frequent cloud-free sky and less surface solar radiation in China from 1955 to 2000, Geophys. Res. Lett., 33, L01812, doi:10.1029/2005GL024586, 2006.

Qian, Y., Wang, W., Leung, L. R., and Kaiser, D. P.: Variability of solar radiation under cloud-free skies in China: The role of aerosols, Geophys. Res. Lett., 34, L12804, doi:10.1029/2006GL028800, 2007.

Qiu, J. H. and Yang, L. Q.: Variation characteristics of atmospheric aerosol optical depths and visibility in North China during 19801994, Atmos. Environ., 34, 603-609, 2000.
Ramanathan, V. and Vogelmann, A. M.: Greenhouse effect, atmospheric solar absorption and the Earth's radiation budget: From the Arrhenius-Langley era to the 1990s, Ambio, 26, 38-46, 1997.

Ramanathan, V., Crutzen, P. J., Kiehl, J. T., and Rosenfeld, D.: Atmosphere - Aerosols, climate, and the hydrological cycle, Science, 294, 2119-2124, 2001.

Rayner, D. P.: Wind run changes: The dominant factor affecting pan evaporation trends in Australia, J. Climate., 20, 3379-3394, 2007.

Ren, G. and Guo, J.: Change in pan evaporation and the influential factors over China: 1956-2000, Journal of Natural Resources, 21, 31-44, 2006.

Ren, G., Guo, J., Xu, M., Chu, Z., Zhang, L., Zou, X., Li, Q., and Liu, X.: Climate changes of China's mainland over the past half century, Acta Meteorol. Sin., 63, 942-956, 2005.

Ren, X. L., He, H. L., Zhang, L., Zhou, L., Yu, G. R., and Fan, J. W.: Spatiotemporal variability analysis of diffuse radiation in China during 1981-2010, Ann. Geophys., 31, 277-289, doi:10.5194/angeo-31-277-2013, 2013.

Roderick, M. L. and Farquhar, G. D.: The cause of decreased pan evaporation over the past 50 years, Science, 298, 1410-1411, 2002.

Roderick, M. L. and Farquhar, G. D.: Changes in New Zealand pan evaporation since the 1970s, Int. J. Climatol., 25, 2031-2039, 2005.

Sanchez-Lorenzo, A., Brunetti, M., Calbo, J., and Martin-Vide, J.: Recent spatial and temporal variability and trends of sunshine duration over the Iberian Peninsula from a homogenized data set, J. Geophys. Res.-Atmos., 112, D20115, doi:10.1029/2007JD008677, 2007.

Sanchez-Lorenzo, A., Calbo, J., and Martin-Vide, J.: Spatial and temporal trends in sunshine duration over Western Europe (1938-2004), J. Climate., 21, 6089-6098, 2008.

Satheesh, S. K.: Atmospheric chemistry and climate, Curr. Sci., 102, 426-439, 2012.

Shaw, D., Pang, A., Lin, C. C., and Hung, M. F.: Economic growth and air quality in China, Environmental Economics and Policy Studies, 12, 79-96, 2010.

Shen, F., Wang, T., Zhuang, B., and Li, S.: The first indirect radiative forcing of dust aerosol and its effect on regional climate in China, China Environmental Science, 31, 1057-1063, 2011.

Shen, S. and Sheng, Q.: Changes in pan evaporation and its cause in China in the last 45 years, Acta Meteorol. Sin., 66, 452-460, 2008.

Shen, S. and Sheng, Q.: Characteristics and causes of changes of pan evaporation in China during 1957-2001, Acta Meteorol. Sin., 23, 575-584, 2009.

Shen, Y., Zhao, Z., and Shi, G.: The progress in variation of surface solar radiation, factors and probable climatic effects, Adv. Earth Sci., 23, 915-923, 2008.

Shen, Y., Liu, C., Liu, M., Zeng, Y., and Tian, C.: Change in pan evaporation over the past 50 years in the arid region of China, Hydrol. Process., 24, 225-231, 2010.

Shi, G., Hayasaka, T., Ohmura, A., Chen, Z., Wang, B., Zhao, J., Che, H., and $\mathrm{Xu}, \mathrm{L}$. : Data quality assessment and the long-term trend of ground solar radiation in China, J. Appl. Meteorol. Climatol., 47, 1006-1016, 2008.

Solomon, S., Rosenlof, K. H., Portmann, R. W., Daniel, J. S., Davis, S. M., Sanford, T. J., and Plattner, G. K.: Contributions of strato- 
spheric water vapor to decadal changes in the rate of global warming, Science, 327, 1219-1223, 2010.

Stanhill, G. and Cohen, S.: Solar radiation changes in Japan during the 20th century: Evidence from sunshine duration measurements, J. Meteorol. Soc. Jpn., 86, 57-67, 2008.

Stern, D. I.: Reversal of the trend in global anthropogenic sulfur emissions, Global Environ. Change, 16, 207-220, 2006.

Streets, D. G., Wu, Y., and Chin, M.: Two-decadal aerosol trends as a likely explanation of the global dimming/brightening transition, Geophys. Res. Lett., 33, L15806, doi:10.1029/2006GL026471, 2006.

Streets, D. G., Yu, C., Wu, Y., Chin, M., Zhao, Z., Hayasaka, T., and Shi, G.: Aerosol trends over China, 1980-2000, Atmos. Res., 88, 174-182, 2008.

Streets, D. G., Yan, F., Chin, M., Diehl, T., Mahowald, N., Schultz, M., Wild, M., Wu, Y., and Yu, C.: Anthropogenic and natural contributions to regional trends in aerosol optical depth, 1980-2006, J. Geophys. Res.-Atmos., 114, D00D18, doi:10.1029/2008JD011624, 2009.

Tang, W., Yang, K., He, J., and Qin, J.: Quality control and estimation of global solar radiation in China, Sol. Energy, 84, 466-475, 2010.

Tang, W.-J., Yang, K., Qin, J., Cheng, C. C. K., and He, J.: Solar radiation trend across China in recent decades: a revisit with quality-controlled data, Atmos. Chem. Phys., 11, 393-406, doi:10.5194/acp-11-393-2011, 2011.

Tao, S., Fu, C., Zeng, Z., and Zhang, Q.: Two long-term instrumental climatic data bases of the People's Republic of China, Oak Ridge National Laboratory, Tennessee, USA, 1997.

Wang, C. H., Zhang, Z. F., and Tian, W. S.: Factors affecting the surface radiation trends over China between 1960 and 2000, Atmos. Environ., 45, 2379-2385, 2011.

Wang, K., Ye, H., Chen, F., Xiong, Y., Li, X., and Tang, L.: Longterm change of solar radiation in southeastern China: Variation, factors, and climate forcing, Ecol. Environ. Sci., 19, 1119-1124, 2010.

Wang, K. C., Dickinson, R. E., Su, L., and Trenberth, K. E.: Contrasting trends of mass and optical properties of aerosols over the Northern Hemisphere from 1992 to 2011, Atmos. Chem. Phys., 12, 9387-9398, doi:10.5194/acp-12-9387-2012, 2012a.

Wang, K. C., Dickinson, R. E., Wild, M., and Liang, S.: Atmospheric impacts on climatic variability of surface incident solar radiation, Atmos. Chem. Phys., 12, 9581-9592, doi:10.5194/acp12-9581-2012, $2012 \mathrm{~b}$.

Wang, X., Dong, Z., Zhang, J., and Liu, L.: Modern dust storms in China: An overview, J. Arid. Environ., 58, 559-574, 2004.

Wang, Y., Huang, Y., and Zhang, W.: Changes in surface solar radiation in Mainland China over the period from 1961 to 2003, Climatic and Environmental Research, 14, 405-413, 2009.

Wang, Y. W., Yang, Y. H., Zhao, N., Liu, C., and Wang, Q. $X$. : The magnitude of the effect of air pollution on sunshine hours in China, J. Geophys. Res.-Atmos., 117, D00V14, doi:10.1029/2011JD016753, 2012.

Wang, Y. W., Yang, Y. H., Han, S. M., Wang, Q. X., and Zhang, J. H.: Sunshine dimming and brightening in Chinese cities (19552011) was driven by air pollution rather than clouds, Clim. Res., $56,11-20,2013$.
Wang, Z., Ding, Y., He, J., and Yu, J.: An updating analysis of the climate change in China in recent 50 years, Acta Meteorol. Sin., 62, 228-236, 2004.

Wen, X., Shang, K., Wang, S., Yang, D., and Fan, W.: Primary study on regional characteristics of solar radiation in China during 1961-2000, Journal of Desert Research, 28, 554-561, 2008.

Wild, M.: Global dimming and brightening: A review, J. Geophys. Res.-Atmos., 114, D00D16, doi:10.1029/2008JD011470, 2009.

Wild, M.: Enlightening global dimming and brightening, B. Am. Meteorol. Soc., 93, 27-37, 2012a.

Wild, M.: New Directions: A facelift for the picture of the global energy balance, Atmos. Environ., 55, 366-367, 2012 b.

Wild, M. and Liepert, B.: The Earth radiation balance as driver of the global hydrological cycle, Environ. Res. Lett., 5, 025003, doi:10.1088/1748-9326/5/2/025003 2010.

Wild, M. and Schmucki, E.: Assessment of global dimming and brightening in IPCC-AR4/CMIP3 models and ERA40, Clim. Dynam., 37, 1671-1688, 2011.

Wild, M., Gilgen, H., Roesch, A., Ohmura, A., Long, C. N., Dutton, E. G., Forgan, B., Kallis, A., Russak, V., and Tsvetkov, A.: From dimming to brightening: Decadal changes in solar radiation at Earth's surface, Science, 308, 847-850, 2005.

Wild, M., Truessel, B., Ohmura, A., Long, C. N., Konig-Langlo, G., Dutton, E. G., and Tsvetkov, A.: Global dimming and brightening: An update beyond 2000, J. Geophys. Res.-Atmos., 114, D00D13, doi:10.1029/2008JD011382, 2009.

Wild, M., Roesch, A., and Ammann, C.: Global dimming and brightening - evidence and agricultural implications, CAB Reviews, 7, 1-7, 2012.

Xia, X.: A closer looking at dimming and brightening in China during 1961-2005, Ann. Geophys., 28, 1121-1132, doi:10.5194/angeo-28-1121-2010, 2010a.

Xia, X. G.: Spatiotemporal changes in sunshine duration and cloud amount as well as their relationship in China during 1954-2005, J. Geophys. Res.-Atmos., 115, D00K06, doi:10.1029/2009JD012879, 2010b.

Xia, X. A., Wang, P. C., Chen, H. B., and Liang, F.: Analysis of downwelling surface solar radiation in China from National Centers for Environmental Prediction reanalysis, satellite estimates, and surface observations, J. Geophys. Res., 111, D09103, doi:10.1029/2005JD006405, 2006.

Xia, X., Chen, H., Li, Z., Wang, P., and Wang, J.: Significant reduction of surface solar irradiance induced by aerosols in a suburban region in northeastern China, J. Geophys. Res.-Atmos., 112, D22S02, doi:10.1029/2006JD007562, 2007a.

Xia, X., Li, Z., Holben, B., Wang, P., Eck, T., Chen, H., Cribb, M., and Zhao, Y.: Aerosol optical properties and radiative effects in the Yangtze Delta region of China, J. Geophys. Res.-Atmos., 112, D22S12, doi:10.1029/2007JD008859, 2007b.

Xia, X., Li, Z., Wang, P., Chen, H., and Cribb, M.: Estimation of aerosol effects on surface irradiance based on measurements and radiative transfer model simulations in Northern China, J. Geophys. Res., 112, D22S10, doi:10.1029/2006JD008337, 2007c.

Xia, X., Wang, P., Wang, Y., Li, Z., Xin, J., Liu, J., and Chen, H.: Aerosol optical depth over the Tibetan Plateau and its relation to aerosols over the Taklimakan Desert, Geophys. Res. Lett., 35, L16804, doi:10.1029/2008GL034981, 2008.

Xia, X., Zong, X., Cong, Z., Chen, H., Kang, S., and Wang, P.: Baseline continental aerosol over the central Tibetan plateau and a 
case study of aerosol transport from South Asia, Atmos. Environ., 45, 7370-7378, 2011.

Xin, J., Wang, Y., Li, Z., Wang, P., Hao, W. M., Nordgren, B. L., Wang, S., Liu, G., Wang, L., Wen, T., Sun, Y., and Hu, B.: Aerosol optical depth (AOD) and Angstrom exponent of aerosols observed by the Chinese Sun Hazemeter Network from August 2004 to September 2005, J. Geophys. Res.-Atmos., 112, D05203, doi:10.1029/2006JD007075, 2007.

Xu, M., Chang, C. P., Fu, C., Qi, Y., Robock, A., Robinson, D., and Zhang, H. M.: Steady decline of East Asian monsoon winds, 1969-2000: Evidence from direct ground measurements of wind speed, J. Geophys. Res.-Atmos., 111, D24111, doi:10.1029/2006JD007337, 2006.

Yan, Z., Xinfa, Q. I. U., Changming, L. I. U., Aoda, P. A. N., and Gao, P.: Changes of pan evaporation in China in 1960-2000, Adv. Water Sci., 18, 311-318, 2007.

Yang, H. and Yang, D.: Climatic factors influencing changing pan evaporation across China from 1961 to 2001, J. Hydrol., 414415, 184-193, 2012.

Yang, K., Ding, B., Qin, J., Tang, W., Lu, N., and Lin, C.: Can aerosol loading explain the solar dimming over the Tibetan Plateau?, Geophys. Res. Lett., 39, L20710, doi:10.1029/2012GL053733, 2012a.

Yang, S., Wang, K., and Lue, S.: Regional characteristics of global solar radiation evolution in China over recent 40 years, Acta Energiae Solaris Sinica, 28, 227-232, 2007.

Yang, X., Li, Z., Feng, Q., He, Y., An, W., Zhang, W., Cao, W., Yu, T., Wang, Y., and Wilfred H., T.: The decreasing wind speed in Southwestern China during 1969-2009, and possible causes, Quaternary Int., 263, 71-84, 2012b.

Yang, Y. H., Zhao, N., Hao, X. H., and Li, C. Q.: Decreasing trend of sunshine hours and related driving forces in North China, Theor. Appl. Climatol., 97, 91-98, 2009a.

Yang, Y. H., Zhao, N., Hu, Y. K., and Zhou, X. Y.: Effect of wind speed on sunshine hours in three cities in Northern China, Clim. Res., 39, 149-157, 2009b.

Ye, J., Li, F., Sun, G., and Guo, A.: Solar dimming and its impact on estimating solar radiation from diurnal temperature range in China, 1961-2007, Theor. Appl. Climatol., 101, 137-142, 2010.
Yin, Y., Wu, S., Chen, G., and Dai, E.: Attribution analyses of potential evapotranspiration changes in China since the 1960s, Theor. Appl. Climatol., 101, 19-28, 2010.

You, Q., Kang, S., Flügel, W. A., Sanchez-Lorenzo, A., Yan, Y., Huang, J., and Martin-Vide, J.: From brightening to dimming in sunshine duration over the eastern and central Tibetan Plateau (1961-2005), Theor. Appl. Climatol., 101, 445-457, 2010.

You, Q., Sanchez-Lorenzo, A., Wild, M., Folini, D., Fraedrich, K., Ren, G., and Kang, S.: Decadal variation of surface solar radiation in the Tibetan Plateau from observations, reanalysis and model simulations, Clim. Dynam., 40, 2073-2086, 2013.

Yu, H., Liu, S., Zhao, N., Yu, Y., Yu, L., and Cao, H.: Variation characteristics of the sunshine duration and its relationships with temperature, wind speed, and precipitation over recent 59 years in China, Climatic and Environmental Research, 16, 389-398, 2011.

Zhang, K. M. and Wen, Z. G.: Review and challenges of policies of environmental protection and sustainable development in China, J. Environ. Manage., 88, 1249-1261, 2008.

Zhao, D., Luo, Y., Gao, G., and Zhu, C.: Essential characteristics of solar direct radiation over recent 50 years in China, Acta Energiae Solaris Sinica, 30, 946-952, 2009.

Zhao, D., Luo, Y., Gao, G., Zhu, C., and Shen, Y.: Long-term changes and essential climatic characteristics of sunshine duration over China during 1961-2007, Resources Science, 32, 701711, 2010.

Zheng, X., Wang, X., Luo, Y., and Chen, J.: Variation characteristics of global radiation and the associated climatic factors over Yunnan-Guizhou Plateau in the southwestern part of China for 1961-2005, Clim. Environ. Res., 16, 657-664, 2011.

Zhu, X., He, H., Liu, M., Yu, G., Sun, X., and Gao, Y.: Spatiotemporal variation of photosynthetically active radiation in China in recent 50 years, J. Geogr. Sci., 20, 803-817, 2010.

Zuo, H. C., Li, D. L., Hu, Y. Q., Bao, Y., and Lu, S. H.: Characteristics of climatic trends and correlation between pan-evaporation and environmental factors in the last 40 years over China, Chinese Sci. Bull., 50, 1235-1241, 2005. 